www.jmscr.igmpublication.org

Impact Factor 5.84

Index Copernicus Value: 83.27

ISSN (e)-2347-176x ISSN (p) 2455-0450

crossref DOI: _https://dx.doi.org/10.18535/jmscr/v5i8.27

Journal Of Medical Science And Clinical Research

IGM Publication

An official Publication of IGM Publication

\title{
Comparison of Gabapentin and Labetalol in Attenuating the Stress Response to Laryngoscopy and Intubation
}

\author{
Authors \\ Shahnawaz Khaliq ${ }^{1}$, Tantry Tariq Gani ${ }^{2}$, Sobia Manzoor ${ }^{3}$, Khalid Sofi ${ }^{4}$ \\ ${ }^{1,2,3}$ Senior Resident, Department of Anesthesiology and Critical Care \\ ${ }^{4}$ Assistant Professor, Department of Anesthesiology and Critical Care \\ Sheri Kashmir Institute of Medical Sciences \\ Corresponding Author \\ Tantry Tariq Gani \\ Email: tantarytariq2@gmail.com
}

\begin{abstract}
Background: Laryngoscopy and tracheal intubation increase blood pressure $(B P)$ and heart rate $(H R)$. The aim of this study was to evaluate the effect of gabapentin and labetalol given before operation on the hemodynamic response to laryngoscopy and intubation.

Methodology: 90 ASA I and II patients undergoing elective surgery were randomly allocated to three groups of 30 each. Group A patients received $800 \mathrm{mg}$ of Gabapentine orally 60 minutes before induction of anaesthesia, Group B patients received $100 \mathrm{mg}$ oral Labetalol 60 minutes prior to induction of anaesthesia and Group $C$ patients were not given any treatment and served as the control group for the study. Anesthesia was induced with inj. propofol and inj. rocuronium. Heart rate, systolic BP, diastolic BP and mean arterial pressure were recorded as baseline, after induction, at tracheal intubation (0 min.); and then at 1, 3, 5, 10 min following tracheal intubation.

Results: mean heart rate, mean systolic blood pressure, mean diastolic blood pressure and mean arterial blood pressure remained significantly lower in group A as compared to group B and group $C$.

Conclusions: Gabapentin, under present study design, attenuates the pressor response associated with laryngoscopy and intubation.

Keywords: Intubation; Laryngoscopy; Gabapentin, Labetalol.
\end{abstract}

\section{Introduction}

In 1940 Brace first established haemodynamic variation with laryngoscopy, irrespective of type of laryngoscopy blade used. Direct laryngoscopy and intubation causes affrent vagal stimulation and effrent vagal sympatho-adrenal response, this causes increase in blood pressure (BP), heart rate (HR) and cardic arrhythmias in some patients, these changes constitute pressor response which is transient, variable and unpredictable. Usually these changes are well tolerated by healthy individuals. However these changes may be fatal in patients with hypertension, coronory artery disease, intracranial hypertension and aneurysm (Pyrs-roberts, Green LT 1971). ${ }^{1}$

Keeping in view the frequency with which pressor response is observed during direct laryngoscopy and intubation various drugs and techniques have 
been utilized to blunt this response with variable degree of success.

Beta blockers have been recommended by various authors. Prys-Roberts et al (1973) used practolol and found it significantly attennuate hemodynamic response associated with laryngoscopy and endotarcheal intubation. ${ }^{2}$ A number of beta blockers have been used since then Labetalol (Scott et al ; 1978), Metoprolol (Coleman; 1980) Esmolol (Miller and Martineau; 1989, Helfman et al; 1991) were reported to be effective. ${ }^{3,4,5}$ Chung K S et al 1992 demonstrated that intermediate dose of Labetalol blunts heart rate response to laryngoscopy and intubation in healthy patients but has minimal effect on blood pressure. $^{6}$ Recently studies have generated interest in use of Gabapentine for attenuation of pressor response to laryngoscopy and intubation. Gabapentine is a second generation anti epileptic that is effective in treatment of neuropathic pain. Turan et al ( 2004) reported that preoperative oral Gabapentine decrease pain scores and post operative tramadol consumption in patients pretreated with Gabapentine. $^{7}$

\section{Aims and Objectives}

1. To compare the relative effectiveness of gabapentine and Labetalol in attenuation of pressor response to direct laryngoscopy and intubation.

2. To find out other desirable effects and complications of both drugs.

\section{Material and Methods}

After obtaining informed consent and approval from hospital ethical committee, the randomized control trial was conducted in department of anaesthesiology and intensive care, SHERI KASHMIR INSTITUTE OF MEDICAL SCIENCES (SKIMS), DEEMED UNIVERSITY. Our study was conducted on 90 patients of ASA grade I and II between age group of 18-65 years of either sex, undergoing elective surgery under general anaesthesia with endotracheal intubation. A preanaesthetic check up was done one day prior to surgery that included detailed history, thorough clinical examination and relevant clinical investigations. Patients with anticipated difficult intubation, ASA grade III or greater, Age greater than 65 years, history of consumption of antihypertensive drugs, sedatives, hypnotics, antidepressants drugs preoperatively, pre-existing cardiovascular disease, patients with significant respiratory, hepatic, renal, haemopoitic and endocrine disorder and patients on treatment with clonidine, methyldopa, $\beta$-blokers, benzodiazepines and MAO inhibitors were excluded from the study. Patients were prepared with 8 hours preoperative fasting. Tablet Alprazolam $0.25 \mathrm{mg}$ was given at bed time day before surgery. Patients also received Omeprazole $40 \mathrm{mg}$ at bed time, a day before surgery. After obtaining informed consent, patients were allocated to receive treatment according to a randomized plan. The patients were randomly allocated to one of the following three groups after arrival in preoperative room

Group A: Patients in this group received $800 \mathrm{mg}$ of Gabapentine orally 60 minutes before induction of anaesthesia.

Group B: Patients in this group received $100 \mathrm{mg}$ oral Labetalol 60 minutes prior to induction of anaesthesia.

Group C: Patients in this group were not given any treatment and served as the control group for the study.

In the preoperative room a crystalloid infusion was started through an intravenous cannula inserted in a peripheral vein and Injection ondansetron $0.1 \mathrm{mg} / \mathrm{kg}$ was given 10 minutes before induction. After receiving patients in operating room, monitors were attached to the patients and all parameters like heart rate, blood pressure, oxygen saturation and ECG were noted. After 3 minutes of preoxygenation, anaesthesia was induced with propofol $2.5 \mathrm{mg} / \mathrm{kg}$ body weight over 30 seconds and injection rocuronium $0.6 \mathrm{mg} / \mathrm{kg}$ body weight. All intubations were performed by experienced anaesthesiologist. The duration of laryngoscopy and intubation was 
limited to minimum possible time being similar in all patients. Depending upon the type and duration of surgery all the patients were maintained with $33 \%$ Oxygen, $66 \%$ nitrous oxide, $1 \%$ isoflurane and Rocuronium $0.15 \mathrm{mg} / \mathrm{kg}$ as intermittent boluses. Parameters like heart rate, systolic blood pressure, diastolic blood pressure, mean arterial pressure were recorded before intubation and at 0 , 1, 3,5 and 10 minutes after intubation. At the end of the surgery neuromuscular blockade was reversed with injection Neostigmine $0.05 \mathrm{mg} / \mathrm{kg}$ and injection Glycopyrolate $0.01 \mathrm{mg} / \mathrm{kg}$ before extubation.

The data was analyzed with the help of computer software SPSS. 12. 0. MICROSOFT excel for windows and presented as mean and standard deviations. The baseline charecteristics evaluated to ascertain comparability among groups were assessed by repeated measures ANOVA. Appropriate tests were used to evaluate statistical significant difference among different groups. A p value $<0.05$ was considered as statistically significant unless specified otherwise. All analysis were done as intention to treat biases.

\section{Results}

Table 1: Comparision of Age And Weight In Three Groups

\begin{tabular}{|l|l|l|}
\hline Group & Age(in years) & weight $($ in $\mathrm{kg})$ \\
\hline Group A & $36.63 \pm 11.17$ & $54.62 \pm 5.15$ \\
\hline Group B & $38.70+6.48$ & $57.13 \pm 5.02$ \\
\hline Group C & $36.03 \pm 7.23$ & $55.93 \pm 4.95$ \\
\hline & p-value-0.774 & p-value 00.445 \\
\hline
\end{tabular}

The mean age (years) and weight $(\mathrm{kg})$ in Group A was $36.63 \pm 11$ 17and $54.62 \pm 515$, in Group B was $38.70+6.48$ and $57.13 \pm 5.02$, and in Group C was $36,03 \pm 7.23$ and $55.93 \pm 4.95$, respectively. On comparing the three groups using ANOVA, the difference among the groups was statistically insignificant ( $p$-value $>0.05$ ).

Table 2: Comparison of the three Groups Before Induction of Anaestiiesia

\begin{tabular}{|l|c|c|c|c|c|}
\hline Variable & Group A & Group B & Group C & P-value & Remarks \\
\hline Heart rate (beats/min.) & $84.23 \pm 6.34$ & $85.20 \pm 8.38$ & $87.03 \pm 9.89$ & 0.63 & N.S \\
\hline SBP(mmHg) & $127.17 \pm 8.15$ & $127.80 \pm 10.66$ & $128.43 \pm 11.18$ & 0.81 & N.S \\
\hline DBP(mmHg) & $83.93 \pm 6.11$ & $82.33 \pm 7.07$ & $80.47 \pm 8.56$ & 0.34 & N.S \\
\hline MAP(mmHg) & $97.87 \pm 5.33$ & $96.77 \pm 8.02$ & $97.23 \pm 9.43$ & 0.86 & N.S \\
\hline
\end{tabular}

The above table depicts the mean Heart Rate, Systolic Blood Pressure and mean Arterial Pressure in the three groups before induction of anaesthesia. When intergroup comparison was done using ANOVA, no statistically significant difference was found amongst the groups ( $\mathrm{p}$-value $>0.05$ ).

Table 3: Significance of Heart Rate Changes in the Groups before and after Laryngoscopy and Intubation

\begin{tabular}{|l|c|c|c|c|c|c|}
\hline Time & \multicolumn{2}{|c|}{ Group A } & \multicolumn{2}{c|}{ Group B } & \multicolumn{2}{c|}{ Group C } \\
\hline & Mean \pm S.D & $\begin{array}{c}\text { P- } \\
\text { value }\end{array}$ & Mean \pm S.D & $\begin{array}{c}\text { p- } \\
\text { value }\end{array}$ & Mean \pm S.D & p-value \\
\hline Before induction & $84.23 \pm 6.34$ & & $85.20 \pm 8.38$ & & $87.03 \pm 9.89$ & 0.002 \\
\hline Before intubation & $77.63 \pm 7.43$ & 0.001 & $78.40 \pm 9.19$ & 0.005 & $79.53 \pm 8.57$ & 0.000 \\
\hline After laryngoscopy and intubation \\
\hline 0 min & $90.27 \pm 7.15$ & 0.002 & $103.80 \pm 9.70$ & 0.000 & $104.87 \pm 11.17$ & 0.000 \\
\hline 1 min. & $88.10 \pm 6.94$ & 0.032 & $100.77 \pm 9.45$ & 0.000 & $102.27 \pm 10.27$ & 0.000 \\
\hline 3 min & $85.40 \pm 6.68$ & 0.490 & $94.60 \pm 7.87$ & 0.000 & $96.60 \pm 10.17$ & 0.001 \\
\hline 5 min & $81.13 \pm 6.23$ & 0.066 & $89.30 \pm 7.53$ & 0.045 & $92.90 \pm 9.70$ & 0.027 \\
\hline 10 min & $78.53 \pm 4.23$ & 0.000 & $84.97 \pm 6.47$ & 0.906 & $84.20 \pm 8.96$ & 0.254 \\
\hline The mean difference is significant at p-value <0.05 and highly significant at p-value <0.001 \\
\hline
\end{tabular}

The above table shows that there was statistically significant rise in heart rate after laryngeoscopy and intubation at $0 \mathrm{~min}$ in all the groups $(\mathrm{p}<0.05)$.
Heart rate decreased to insignificant levels in group A (p-value > 0.05) at 3 min., whereas it remained significant in group $\mathrm{C}$ and $\mathrm{D}$ upto $5 \mathrm{~min}$. 
Table 4: Significance of Systolic Blood Pressure Changes in the three Groups before and after Laryngoscopy and Intubation.

\begin{tabular}{|l|c|c|c|c|c|c|}
\hline Time & \multicolumn{2}{|c|}{ Group A } & \multicolumn{2}{c|}{ Group B } & \multicolumn{2}{c|}{ Group C } \\
\hline & Mean \pm S.D & P-value & Mean \pm S.D & p-value & Mean \pm S.D & p-value \\
\hline Before induction & $127.17 \pm 8.15$ & & $127.80 \pm 10.66$ & & $128.43 \pm 11.10$ & \\
\hline Before intubation & $115.20 \pm 9.35$ & 0.000 & $118.50 \pm 11.82$ & 0.000 & $118.50 \pm 10.91$ & 0.000 \\
\hline After laryngoscopy and intubation & $125.01 \pm 7.95$ & 0.307 & $156.03 \pm 12.86$ & 0.000 & $160.26 \pm 11.42$ & 0.000 \\
\hline 0 min & $115.67 \pm 6.32$ & 0.000 & $151.20 \pm 12.08$ & 0.000 & $155.67 \pm 11.90$ & 0.000 \\
\hline 1 min. & $110.53 \pm 6.49$ & 0.000 & $144.47 \pm 10.75$ & 0.000 & $148.40 \pm 11.06$ & 0.000 \\
\hline 3 min & $107.30 \pm 6.35$ & 0.000 & $139.90 \pm 11.58$ & 0.000 & $139.00 \pm 12.44$ & 0.000 \\
\hline 5 min & $104.90 \pm 5.58$ & 0.000 & $135.10 \pm 9.99$ & 0.004 & $136.93 \pm 10.64$ & 0.001 \\
\hline $10 \mathrm{~min}$ & \multicolumn{7}{|l|}{} \\
\hline
\end{tabular}

From the above table it is observed that after laryngoscopy and intubation systolic blood pressure shot up significantly (p-value $<0.001)$ in all the groups except in group A. In group A there was a fall in systolic blood pressure 1 min after laryngoscopy and intubation which continued upto the $10^{\text {th }} \mathrm{min}$.

Table 5: Significance of Diastolic Blood Pressure Changes in the three Groups before and after Laryngoscopy and Intubation.

\begin{tabular}{|l|c|c|c|c|c|c|}
\hline Time & \multicolumn{2}{|c|}{ Group A } & \multicolumn{2}{c|}{ Group B } & \multicolumn{2}{c|}{ Group C } \\
\hline & Mean \pm S.D & P-value & Mean \pm S.D & p-value & Mean \pm S.D & p-value \\
\hline Before induction & $83.93 \pm 6.11$ & & $82.33 \pm 7.07$ & & $80.47 \pm 8.56$ & \\
\hline Before intubation & $80.86 \pm 6.54$ & 0.000 & $80.31 \pm 1.82$ & 0.000 & $76.52 \pm 1.93$ & 0.000 \\
\hline After laryngoscopy and intubation \\
\hline 0 min & $80.06 \pm 7395$ & 0.50 & $96.23 \pm 2.84$ & 0.000 & $98.43 \pm 1.4$ & 0.000 \\
\hline 1 min. & $75.34 \pm 6232$ & 0.000 & $94.21 \pm 3.08$ & 0.000 & $94.32 \pm 3.90$ & 0.000 \\
\hline 3 min & $74.12 \pm 1.49$ & 0.000 & $93.23 \pm 4.73$ & 0.000 & $94.33 \pm 5.06$ & 0.000 \\
\hline 5 min & $73.2 \pm 4.35$ & 0.000 & $92.31 \pm 4 . .58$ & 0.000 & $93.21 \pm 2.41$ & 0.000 \\
\hline 10 min & $72.3 \pm 3.53$ & 0.000 & $90.33 \pm 1.23$ & 0.004 & $92.31 \pm 1.64$ & 0.001 \\
\hline The mean difference is significant at p-value <0.05 and highly significant at p-value <0.001 \\
\hline
\end{tabular}

From the above table it is observed that after laryngoscopy and intubation diastolic blood pressure shot up significantly ( $\mathrm{p}$-value $<0.001$ ) in all the groups except in group A. In group A there was a fall in diastolic blood pressure $1 \mathrm{~min}$. After laryngoscopy and intubation which continued upto the $10^{\text {th }} \mathrm{min}$.

Table 6: Significance of Mean Arterial Blood Pressure Changes in the three Groups Before and After Laryngoscopy and Intubation.

\begin{tabular}{|l|c|c|c|c|c|c|}
\hline Time & \multicolumn{2}{|c|}{ Group A } & \multicolumn{2}{c|}{ Group B } & \multicolumn{2}{c|}{ Group C } \\
\hline & Mean \pm S.D & P-value & Mean \pm S.D & p-value & Mean \pm S.D & p-value \\
\hline Before induction & $97.87 \pm 5.33$ & & $96.77 \pm 8.02$ & & $97.23 \pm 9.43$ & \\
\hline Before intubation & $92.306 \pm 4.23$ & 0.000 & $93.04 \pm 1.47$ & 0.000 & $90.51 \pm 1.91$ & 0.000 \\
\hline After laryngoscopy and intubation & $95.04 \pm 9.17$ & 0.25 & $116.16 \pm 9.34$ & 0.000 & $119.04 \pm 8.42$ & 0.000 \\
\hline 0 min & $88.78 \pm 7.32$ & 0.000 & $113.21 \pm 8.08$ & 0.000 & $114.77 \pm 5.43$ & 0.000 \\
\hline 1 min. & $86.26 \pm 4.33$ & 0.000 & $110.31 \pm 4.18$ & 0.000 & $112.35 \pm 5.89$ & 0.000 \\
\hline 3 min & $84.57 \pm 1.67$ & 0.000 & $108.17 \pm 3.90$ & 0.000 & $108.47 \pm 3.55$ & 0.000 \\
\hline 5 min & $83.17 \pm 2.53$ & 0.000 & $105.25 \pm 7.23$ & 0.004 & $107.18 \pm 1.34$ & 0.001 \\
\hline 10 min & is significant at p-value <0.05 and highly significant at p-value <0.001 \\
\hline The mean difference
\end{tabular}

From the above table it is observed that after laryngoscopy and intubation mean arterial blood pressure shot up significantly ( $\mathrm{p}$-value $<0.001$ ) in all the groups except in group A. In group A there was a fall in systolic blood pressure $1 \mathrm{~min}$. after laryngoscopy and intubation which continued upto the $10^{\text {th }} \mathrm{min}$. 


\section{Discussion}

Laryngoscopy and intubation are mandatory for most patients undergoing general anaesthesia. Direct laryngoscopy and intubation causes afferent vagal stimulation and efferent sympathetico-adrenal response, this causes increase in blood pressure (BP), heart rate (HR) and cardiac arrhythmias in some patients, these changes constitute pressor response which is transient, variable and unpredictable. Usually these changes are well tolerated by healthy individuals. However these changes may be fatal in patients with hypertension, coronary artery disease, intracranial hypertension and aneurysm (Pyrs-roberts, Green LT 1971). ${ }^{1}$

Present study was undertaken to study the effects of labetalol $100 \mathrm{mg}$ and gabapentine $800 \mathrm{mg}$ on attenuation of pressor response to laryngoscopy and endotracheal intubation. 90 patients ASA Grade I-II of either sex, between 20-60 years of age undergoing elective surgery were divided in three groups of 30 patients each. Patients in group A received $800 \mathrm{mg}$ gabapentine, group $B$ patients received labetalol 100mg and group $\mathrm{C}$ acted as control. Pretreatment was given orally one hour before induction of anaesthesia. After 3 minutes of preoxygenation, anaesthesia was induced with propofol $2.5 \mathrm{mg} / \mathrm{kg}$ body weight over 30 seconds and injection rocuronium $0.6 \mathrm{mg} / \mathrm{kg}$ body weight. All intubations were performed by an experienced anaesthesiologist. All the patients were maintained with $33 \%$ Oxygen, $66 \%$ nitrous oxide, $0.5 \%$ halothane and Rocuronium $0.15 \mathrm{mg} / \mathrm{kg}$ as intermittent boluses. Parameters like heart rate, systolic blood pressure, diastolic blood pressure, mean arterial pressure were recorded before intubation and at $0,1,3,5$ and 10 minutes after intubation. At the end of the surgery neuromuscular blockade was reversed with injection Neostigmine $0.05 \mathrm{mg} / \mathrm{kg}$ and injection Glycopyrolate $0.01 \mathrm{mg} / \mathrm{kg}$ before extubation. The evaluation of these parameters has been made seprately for each group. These have been further assessed for comparative analysis identifying the drug efficacy by way of visualising the effect in attenuating the pressor response parameters.

Demographic data like age, ASA status and weight of the patients in the all three groups was stastistically comparable. There was statistically nonsignificant difference in heart rate, systolic blood pressure, diastolic blood pressure and mean arterial pressure among the three groups before intubation.

In group A there was a significant (p-value < 0.05 ) increase in heart rate from preinduction value at $0 \mathrm{~min}$ and $1 \mathrm{~min}$ after laryngoscopy. There after a decline in heart rate was observed which was stastically insignificant ( $p$-value $>0.05$ ) up to $5 \mathrm{~min}$. At $10 \mathrm{~min}$ there was a significant ( pvalue < 0.05) decrease in heart rate from preinduction value. In group $\mathrm{B}$ and group $\mathrm{C}$ there was a significant ( $p$-value $<0.05)$ increase in heart rate from preinduction value at $0 \mathrm{~min}$ to $5 \mathrm{~min}$ after laryngoscopy. There after a decline in heart rate was observed which was stastically insignificant ( $p$-value >0.05) at $10 \mathrm{~min}$. Mean heart rate in group A remained significantly lower as compared to group B and group $\mathrm{C}$, however mean heart rate between group $\mathrm{B}$ and group $\mathrm{C}$ remained statistically non significant. Systolic blood pressure, diastolic blood pressure and mean arterial pressure amongst the three groups before induction and intubation was statistically non significant. Systolic blood pressure, diastolic blood pressure and mean arterial pressure showed a non significant change at $0 \mathrm{~min}$ after laryngoscpy in group A followed by a significant decrease upto $10 \mathrm{~min}$ of laryngoscopy. In group B and $\mathrm{C}$ there was a significant increase in Systolic blood pressure, diastolic blood pressure and mean arterial pressure at all time intervals from baseline value. Overall Systolic blood pressure, diastolic blood pressure and mean arterial pressure remained significantly lower in group $\mathrm{A}$ as compared to group B and group C, however mean Systolic blood pressure, mean diastolic blood pressure and mean arterial pressure between group B and group C remained statistically non significant. Our observation are in accordance 
with of Memis et al (2006) who reported compleate attenuation of reflex increase in heart rate and MAP after laryngoscopy and intubation with 800mg Gabapentine when given one hour before surgery. ${ }^{8}$ However in another study done by Fassoulaki et al (2006) they reported that Gabapentine attenuated increase in blood pressure but not the tachycardia response to laryngoscopy and intubation. ${ }^{9}$ The mechanism by which Gabapentine attenuates the pressor response to laryngoscopy and intubation is unknown. Although the molecular targets of gabapentine remain unknown, the inhibition of calcium flux in muscle cells with a consequent inhibtion of smooth muscle contraction might explain the effectiveness of Gabapentine in attenuation of the pressor response to laryngoscopy. Our study results are also similar to Kong VKF and Irwin MG 2007 who concluded preoperative Gabapentine is efficacious for not only post operative analgesia, post operative nausea and vomiting but also for attenuation of pressor response. $^{10}$

Kim,Chung and Lee 94 concluded in their study that intravenous Labetalol $0.25 \mathrm{mg} / \mathrm{kg}$ is ineffective in controlling DBP and MAP. ${ }^{11}$ Results in group B (Labetalol) were not in accordance to Amar D et al 1991 in which labetalol was given $90 \mathrm{mts}$ before induction of anaesthesia as aganist to our study were it was given 60 min before induction. ${ }^{12}$ Results were also not in accordance to the study of Chung KS et al 1992 where intermediate dose of labetalol was given $90 \mathrm{~min}$ before induction of anaesthesia. $^{13}$ Ramanathan J 1988 observed attenuation of pressor response at intermediate dose of iv labetalol during caessarian, but orall labetalol used in our study did not show significant attenuation of pressor response. ${ }^{14}$

\section{Conclusion}

Thus we concluded that pretreatment with both Gabapentine $800 \mathrm{mg}$ and labetalol $100 \mathrm{mg}$ is effective in attenuation of pressor response to laryngoscopy and intubation. However, the rise in blood pressure is better attenuated by Gabapentine. However further studies will be required to study the synergistic effect of labetalol and gabapentine in different dosage regimens in attenuation of pressor response to direct laryngoscopy and intubation.

\section{Bibliography}

1. Pyrs-Roberts C and Greane LT. Studies of anaesthesia in relation to hypertension ,haemodynamic consequences of induction and endotracheal intubation.Br $\mathrm{J}$ Anaesthesia 1971:43:531-46.

2. Prys-Roberts C and Foex P. Studies of anaesthesia in realtion to hypertension adrengergic beta receptor blockade .Anaesthesia 1973; 45:671-80.

3. Scott, D.B., Buckely, F.P., Littlewood, D.G., Macrae, W.R., Arthur, G.R. \& Drummond, G.B. (1978). Circulatory effects of labetalol during halothane anaesthesia. Anaesthesia, 33, 145-56.

4. Coleman AJ. Cardiovascular response to anaesthesia Anaesthesia 1980; 35: 972-78

5. Miller DR, Martineau RJ, Wynands JE, Hill J. Bolus administration of esmolol for controlling the haemodynamic response to trachealintubation: the Canadian multicenter trial. Can J Anaesth 1991;38: 849-58.

6. Chung KS, Sinatra RS, Chung JH. The effect of an intermediate dose of labetalol on heart rate and blood pressure response to laryngoscopy and intubation. B. J Clin Anesth 1992;4:11-5.

7. Turan A, Karamanlıo lu B, Memi D, Usar P, Pamukçu Z, Türe M. The analgesic effects of gabapentin after total abdominal hysterectomy. Anesth Analg (2004) 98:1370-3.

8. Memis D, Turan A, Karamanlioglu B, Seker S, Ture M. Gabapentin reduces cardiovascular responses to laryngoscopy and tracheal intubation. Eur J Anaesthesiol 2006;23:686-90 
9. Fassoulaki A, Melemeni A, Paraskeva A, Petropoulos G. Gabapentin attenuates the pressor response to direct laryngoscopy and tracheal intubation. $\mathrm{Br} \quad \mathrm{J}$ Anaesth. 2006 Jun;96(6):769-73.

10. Kong VKF AND Irwin MG. Gabapentine: A Multimodal Perioperative drug BR J Anaesthesia 2007 99(6):775-86.

11. Kim HY, Chung CW, Lee HY, Yim CH. The Effect of labetalol on the hemodynamic response to endotracheal intubation. Korean J Anesthesiol. 1994; 27:1611-9.

12. Amar D, Shamoon H, Frishman WH et al. Effect of Labetalol on perioperative stress markers and isoflurane requirements. $\mathrm{Br} \mathrm{j}$ Anaesthesia;67;296-30.

13. Chung KS, Sinatra RS, Chung JH. The effect of an intermediate dose of labetalol on heart rate and blood pressure response to laryngoscopy and intubation. B. J Clin Anesth 1992;4:11-5.

14. Ramanathan J, Sibai B M, Mabie W C, Chauhan D and Ruiz A G 1988. The use of labetalol for attenuation of hypertensive response to endotracheal intubation in preeclampsia. Am. J. Obstet. Gynecol., 159(3), 650-4. 